\title{
Closure between measured and modeled cloud condensation nuclei (CCN) using size-resolved aerosol compositions in downtown
}

\section{Toronto}

\author{
K. Broekhuizen ${ }^{3}$, R.Y.-W. Chang ${ }^{1}$, W. R. Leaitch ${ }^{2}$, S.-M. Li ${ }^{2}$, and J. P. D. Abbatt ${ }^{1}$ \\ ${ }^{1}$ Department of Chemistry, University of Toronto, 80 St. George St., Toronto, ON M5S 3H6, Canada \\ ${ }^{2}$ Meteorological Service of Canada, 4905 Dufferin St., Toronto, ON M3H 5T4, Canada \\ ${ }^{3}$ Department of Chemistry, Colgate University, 13 Oak Dr., Hamilton, NY 13346, USA
}

Received: 16 June 2005 - Published in Atmos. Chem. Phys. Discuss.: 19 August 2005

Revised: 22 December 2005 - Accepted: 2 May 2006 - Published: 30 June 2006

\begin{abstract}
Measurements of cloud condensation nuclei $(\mathrm{CCN})$ were made in downtown Toronto during August and September, 2003. CCN measurements were performed at $0.58 \%$ supersaturation using a thermal-gradient diffusion chamber, whereas the aerosol size distribution and composition were simultaneously measured with a TSI SMPS and APS system and an Aerodyne Aerosol Mass Spectrometer (AMS), respectively. Aerosol composition data shows that the particles were predominately organic in nature, in particular for those with a vacuum aerodynamic diameter of $<0.25 \mu \mathrm{m}$. In this study, the largest contribution to $\mathrm{CCN}$ concentrations came from this size range, suggesting that the $\mathrm{CCN}$ are also organic-rich. Using the size and composition information, detailed $\mathrm{CCN}$ closure analyses were performed. In the first analysis, the particles were assumed to be internally mixed, the organic fraction was assumed to be insoluble, and the inorganic fraction was assumed to be ammonium sulfate. The AMS time-of-flight data were used for Köhler theory predictions for each particle size and composition to obtain the dry diameter required for activation. By so doing, this closure analysis yielded an average value of $C C N_{\text {predicted }} / \mathrm{CCN}_{\text {observed }}=1.12 \pm 0.05$. However, several sample days showed distinct bimodal distributions, and a closure analysis was performed after decoupling the two particle modes. This analysis yielded an average value of $\mathrm{CCN}_{\text {predicted }} / \mathrm{CCN}_{\text {observed }}=1.03 \pm 0.05$. A sensitivity analysis was also performed to determine the aerosol/CCN closure if the organic solubility, droplet surface tension, or chamber supersaturation were varied.
\end{abstract}

Correspondence to: K. Broekhuizen

(kbroekhuizen@mail.colgate.edu)

\section{Introduction}

Aerosols and clouds play vital roles in the climate system, both through direct and indirect radiative forcing. Clouds also impact the hydrological cycle through condensation, transport and precipitation processes. Cloud droplets form when aerosol particles are exposed to conditions of water vapor supersaturation. Particles defined as CCN have sufficient soluble mass to activate, or grow to micron size droplets, at a particular supersaturation. Cloud formation processes are complex and highly dynamic in nature; however, in general, the concentration of $\mathrm{CCN}$ in an air parcel will impact cloud properties. A higher concentration of $\mathrm{CCN}$ at a given supersaturation will lead to more droplets with a smaller mean droplet diameter. This may lead to a more reflective cloud and is termed the first indirect effect, or Twomey effect (Twomey, 1977). The second indirect effect is related to the inhibition of precipitation in clouds with small mean droplet diameters which affects the extent and lifetime of clouds (Albrecht, 1989).

The impact of anthropogenic emissions on cloud and aerosol properties can be significant. Indirect effects have been documented on a local and regional scale (e.g. Rosenfeld, 1999, 2000; Durkee et al., 2000; Givati and Rosenfeld, 2004; Chung and Ramanathan, 2004); however, the understanding of cloud formation processes and aerosol effects are not sufficient to predict indirect effects on a global scale. To accurately understand the indirect effects on a regional and global scale, a better understanding must be achieved on how cloud properties and formation processes are affected by aerosol chemical and physical properties. 
The first step towards this goal is the ability to accurately determine how particles of a defined size distribution and composition will act as CCN. A large number of laboratory studies have investigated the CCN behavior of soluble inorganic species such as ammonium sulfate and sodium chloride (Katz and Kocmond, 1973; Gerber et al., 1977). Recently, significant work has also been done with both soluble and insoluble organic species (Cruz and Pandis, 1997; Corrigan and Novakov, 1999; Giebl et al., 2002; Kumar et al., 2003; Raymond and Pandis, 2002; Broekhuizen et al., 2004a). Examples include low molecular weight dicarboxylic acids, oleic acid, and biogenic secondary organic aerosol (Broekhuizen et al., 2004b; VanReken et al., 2005). These studies focus on single component systems or well defined binary or tertiary mixtures (Raymond and Pandis, 2003; Bilde and Svenningsson, 2004; Abbatt et al., 2005). They have shown that Köhler theory accurately predicts activation behavior for a wide range of species under most conditions. This body of laboratory work gives a solid foundation on which to make predictions. However, atmospheric aerosols are complex mixtures of soluble inorganic and organic species (e.g. Saxena and Hildemann, 1996; Murphy et al., 1998), as well as insoluble components such as organics, soot, and mineral dust. The particles may contain surface active species (Shulman et al., 1996; Facchini et al., 1999) which lower the surface tension of the droplets, as well as soluble gases which may affect activation (Laaksonen et al., 1998). In short, it may be difficult to predict CCN concentrations due to the highly complex and variable nature of true atmospheric aerosols.

\section{Background}

Aerosol/CCN closure studies involve exposing an atmospheric aerosol population to a particular supersaturation or set of supersaturations under controlled conditions and measuring the CCN concentration. The CCN concentration is compared to Köhler theory predictions based on concurrent measurements of dry particle size distributions and compositions. A successful closure study will accurately predict the concentration of $\mathrm{CCN}$.

Previous closure studies have met with varying amounts of success. A variety of methods were used for both aircraft and ground-based measurements. The first attempts at achieving aerosol/CCN closure included studies by Bigg (1986), Quinn et al. (1993), and Martin et al. (1994). While providing useful CCN and aerosol size and composition information, these studies were largely unsuccessful at achieving closure. In a ground based study at Cape Grim, Tasmania, Bigg (1986) compared measured CCN concentrations with predicted concentrations based on particle size distribution measurements and the assumption that the particles were either composed of ammonium sulfate or sodium chloride. The results agree reasonably well at low particle concentrations $\left(<300 \mathrm{~cm}^{-3}\right)$, but under higher aerosol loading the deviation between observations and measurements is a factor of 3-5. Quinn et al. (1993) did not achieve closure during ground based measurements performed at Cheeka Peak, Washington. Only one measurement was performed at $0.3 \%$ supersaturation and the predicted CCN concentration based on an ammonium sulfate assumption was a factor of 2 higher than measured concentrations. Martin et al. (1993) compares two sets of data from flights over the British isles and the North Sea. Assuming an ammonium sulfate composition, reasonable closure is achieved for a maritime air mass, but not for an air mass with continental origins.

More recent closure studies have had more success in achieving closure with some notable exceptions. Liu et al. (1996) made ground based aerosol and CCN measurements at Chebogue Point, Nova Scotia, during the 1993 NARE campaign. Composition information was derived from filter samples and the particles were divided into soluble and insoluble fractions, of which the soluble was assumed to be ammonium sulfate. There was closure within uncertainties for 10 of the 12 data sets with one overprediction and one underprediction. The aerosol mass loading during this study was strongly inorganic in character with small organic contributions. Covert et al. (1998) and Zhou et al. (2001) both used relative humidity controlled tandem differential mobility analyzers (RH-TDMA) to obtain hygroscopic growth factors. The study by Covert et al. (1998) was a ground based measurement as part of ACE 1, while that of Zhou et al. (2001) was a ship borne measurement as part of AOE-96. In both cases, hygroscopic growth factor derived aerosol compositions were used to predict $\mathrm{CCN}$ concentrations. The compositional analysis revealed that soluble inorganic sulfate was the dominant mass fraction under most conditions in both studies. Despite this fact, Covert et al. (1998) overpredicted the CCN concentrations by $25 \%$ for all data, while Zhou et al. (2001) overpredicted by $30 \%$.

Cantrell et al. (2001) achieved closure during INDOEX at the Kaashidhoo Climate Observatory. Compositional analysis was achieved in five size ranges from 0.056 to $1.0 \mu \mathrm{m}$ using microorifice uniform deposit cascade impactors (MOUDIs). A soluble mass fraction, $\varepsilon$, was calculated and utilized in a simplified Köhler theory, assuming the soluble fraction was ammonium sulfate. The soluble fraction, $\varepsilon$, generally varied between about 0.25 and 0.5 , and aerosol/CCN closure was achieved in 8 of 10 data sets. The $\mathrm{CCN}$ concentrations were overpredicted in both cases where closure was not achieved.

Significant airborne experiments were performed as part of ACE-2. Wood et al. (2000) conducted Lagrangian experiments in the marine boundary layer. The measured CCN spectrum was compared to model predictions for soluble ammonium sulfate with varying amounts of insoluble material. The best fit was for a $5 \%$ soluble mass fraction, while fractions of $20 \%, 50 \%$ and $100 \%$ overpredicted CCN concentrations. However, ground based composition measurements 
did not support a 5\% soluble mass fraction, so closure was not achieved in this study. Using aerosol composition data based on ground based filter samples collected at Tenerife, Chuang et al. (2000) overpredicted the measured CCN concentrations by a factor of 3-10 and could not explain this discrepancy by the presence of insoluble material, as the sub-micron insoluble fraction was measured to be $<3 \%$ at Tenerife. In the study of Snider and Brenguier (2000), calculated $\mathrm{CCN}$ concentrations based on ammonium sulfate as the soluble fraction were a factor of 2 higher than measured $\mathrm{CCN}$ concentrations unless the aerosol insoluble mass fraction was elevated to unreasonable levels. Closure was achieved for two days unaffected by continental pollution when subsequent refinements are made to the Köhler calculations (Snider et al., 2003). Dusek et al. (2003) also made ground based CCN measurements at Sagres, Portugal during ACE-2. CCN concentrations were overpredicted by about $30 \%$ on average for all data. A large contribution from organic species is an unlikely source of error, as the sub-micron aerosol carbon mass was generally below $15 \%$.

Two recent studies by Roberts et al. (2002) and VanReken et al. (2003) were successful in achieving aerosol/CCN closure. Roberts et al. (2002) made ground based measurements as part of CLAIRE-98 in the Amazon Basin. CCN concentrations were measured between $0.15 \%$ and $1.5 \%$ supersaturation. Mass distributions were measured with a MOUDI impactor and size distributions with an SMPS system. Compositional analysis revealed organic mass fractions of nearly $80 \%$, of which half was estimated to be soluble. Ammonium bisulfate constituted about $15 \%$ of the remaining aerosol mass. A three component Köhler model was used to predict $\mathrm{CCN}$ concentrations and agreed with measurements within uncertainty, although only when the model assumed that the organic fraction was insoluble. The VanReken et al. (2003) CRYSTAL-FACE study is the first airborne measurement to achieve closure. CCN concentrations were calculated based on the assumption of pure ammonium sulfate using the SMPS aerosol size distributions. This assumption was generally supported by aerosol mass spectrometry (AMS) measurements. There is a systematic overprediction of CCN concentrations of about $5 \%$ for the $0.2 \%$ supersaturation data and about $20 \%$ for the $0.85 \%$ supersaturation data.

More recently, Rissman et al. (2005) have found a degree of overprediction when applying Köhler theory to aerosol measurements and comparing with airborne observations of CCN concentrations. Rissler et al. (2004) has also recently been able to predict $\mathrm{CCN}$ concentrations within $25 \%$ using RH-TDMA derived particle solubilities.

In general, aerosol/CCN closure has been difficult to achieve. This may be due to a number of factors. Many of the studies described above state that incomplete compositional analysis and the unknown effect of organic species or insoluble material limits the success of achieving closure. Measurement biases in the $\mathrm{CCN}$ chambers and detectors or in the measurement of particle size distributions may also be a contributing factor. For airborne measurements, spatial and temporal variability aboard a moving platform may also be a contributing factor in the failure to achieve closure. The studies able to achieve closure were generally not influenced by strong anthropogenic sources and were characterized by low concentrations of organic carbon in the aerosol phase. Only the Roberts et al. (2002) study was characterized by high concentrations of organic material ( $80 \%$ by mass), but water-soluble organic compounds comprised about half of the total organic carbon and the site was not influenced by anthropogenic emissions.

Recent analytical advances have made fast time resolved characterization of single aerosol particles or aerosol populations possible. The Aerodyne Aerosol Mass Spectrometer (AMS) has been widely used in this regard but, aside from a recent study (Medina, J., Nenes, A., Cottrell, L., and R. Griffin, A detailed closure study of CCN in the Northeastern United States, Poster \#A31B-0833 Presented at the American Geophysical Union Annual Meeting, December 2005; hereafter referred to as Medina et al. (2005)), has not been explicitly used for aerosol/CCN closure to this point. As noted above, there have also been recent laboratory studies on the effect of organic species on CCN activity for single or multi-component aerosols. While there are many yet unanswered questions, the roles of solubility, surface tension, and oxidation state in $\mathrm{CCN}$ activation are now better understood than for many previous closure studies. These two factors make the possibility of aerosol/CCN closure in a variety of environments possible.

To this end, a CCN chamber, developed at the University of Toronto, was deployed in an urban environment in downtown Toronto in conjunction with measurements of aerosol physical and chemical properties to determine whether aerosol/CCN closure could be achieved in air masses strongly influenced by local and regional anthropogenic emissions. Toronto can be affected by both clean, Northern air which has low background particulate and minimal anthropogenic influence and air from the southwest that has been influenced by large urban centers and areas of high sulfur emissions from power generation sources.

\section{Experimental description}

\subsection{Sampling site}

The sampling site was located in downtown Toronto, Ontario, Canada on the University of Toronto St. George Campus. Measurements were made over several weeks from 20 August to 25 September 2003 at the Wallberg Building at 184-200 College St. This site is heavily influenced by weekday traffic with a weekday traffic volume of approximately 33000 vehicles/day (Tan et al., 2002). The duct used for sample collection was approximately $6 \mathrm{~m}$ above the ground 


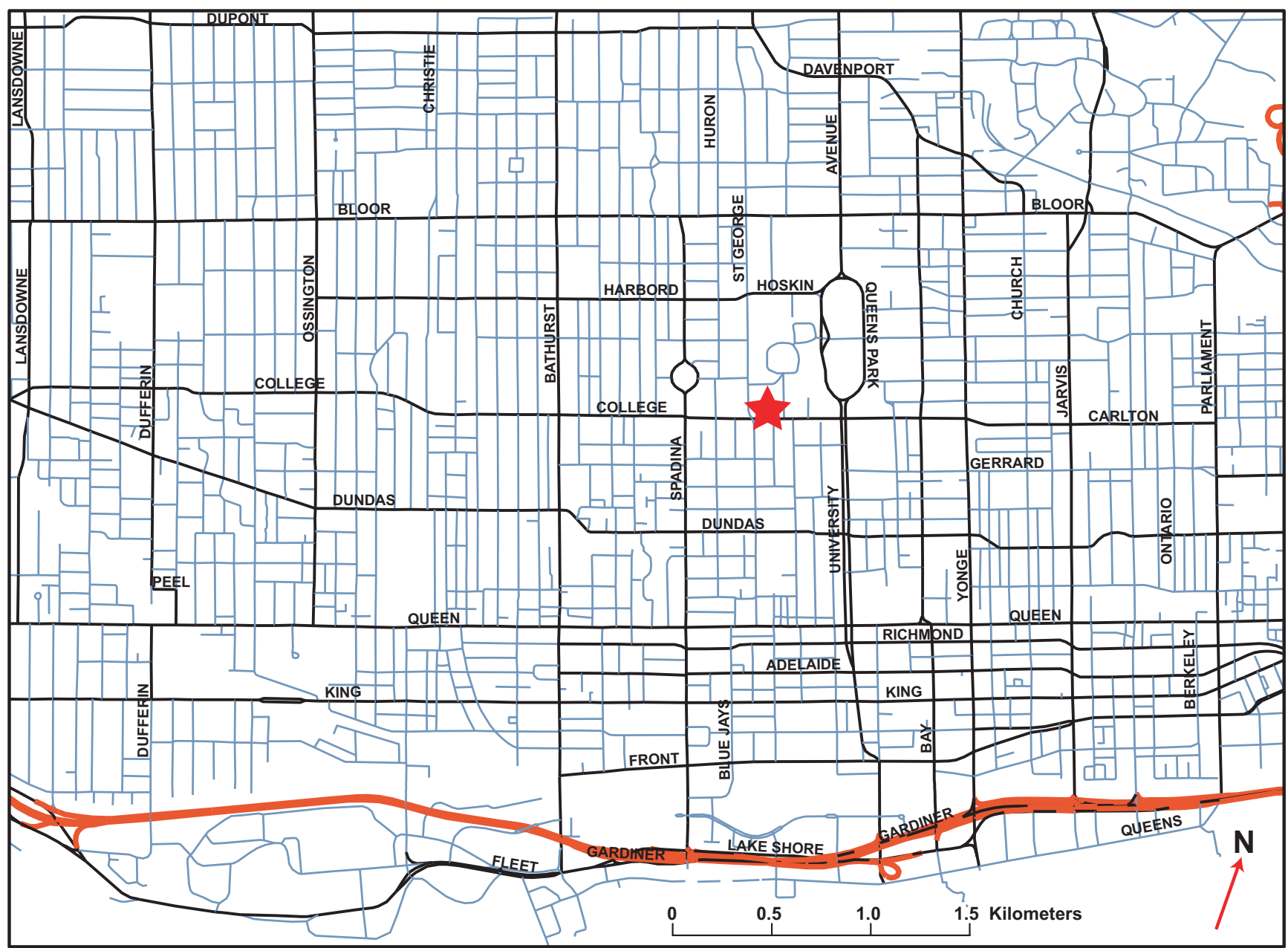

Fig. 1. Map of downtown Toronto showing the sample site $(\star)$ at 184-200 College St. The map was created with CanMap Route Logistics Ontario (v8.2), DMTI Spatial Inc.

and $15 \mathrm{~m}$ north of College Street. A map of the downtown sampling site is shown in Fig. 1. Detailed analysis of aerosol properties, meteorological data, and source apportionment for this field campaign can be found in Buset et al. (2005) $)^{1}$

\subsection{Instrumentation}

Particle composition was measured by several instruments, including an Aerodyne AMS. The AMS has been widely used in laboratory and field campaigns (e.g. Jayne et al., 2000; Allan et al., 2003; Jimenez et al., 2003; Alfarra et al., 2004). It was operated in two modes. In one mode, average mass concentrations of non-refractory particulate species such as sulfate, nitrate, chloride, ammonium, and organic carbon were measured every 15 minutes. The AMS has

\footnotetext{
${ }^{1}$ Buset, K. C., Evans, G. J., Leaitch, W. R., Brook, J. R., and Toom-Sauntry, D.: Use of advanced receptor modeling for analysis of an intensive 5-week aerosol sampling campaign, Atm. Environ., submitted, 2005.
}

nearly $100 \%$ transmission of particles with vacuum aerodynamic diameters in the $0.06 \mu \mathrm{m}$ to $0.6 \mu \mathrm{m}$ range (Zhang, $\mathrm{X}$., et al., 2004). The oven used for particle vaporization was set to $550^{\circ} \mathrm{C}$ and the particle collection efficiency was assumed to be $100 \%$. In the second AMS mode, size-resolved compositional analysis was performed for particles between $0.01 \mu \mathrm{m}$ and $1.0 \mu \mathrm{m}$ in the time-of-flight (TOF) configuration. TOF spectra were collected as hourly averages. For a detailed description of the AMS data collection and calibration, see Buset et al. (2005) ${ }^{1}$.

Water soluble inorganic particulate mass was also analyzed using a water Particle-In-Liquid-Sampler (PILS) with two ion chromatographs for inorganic ion analysis. The PILS also collected $15 \mathrm{~min}$ average samples to coincide with the AMS and other instrumentation. A correlation plot between $\mathrm{SO}_{4}^{2-}$ from the PILS and $\mathrm{SO}_{4}^{2-}$ from the AMS yielded a slope of 0.97 (Buset et al., 2005 ${ }^{1}$ ), giving credence to the assumption that the collection efficiency of the AMS was near $100 \%$. This correlation was valid for most of the 
sampling period and for all the data presented in this paper, during which the mass tended to have a high organic content. Detailed comparisons to the TEOM data are also included in the Buset et al. (2005) ${ }^{1}$ paper which validate a collection efficiency of $100 \%$ for the days during which the CCN measurements were conducted.

Particle size distributions were measured using a Scanning Mobility Particle Sizer (SMPS). The SMPS consisted of a Differential Mobility Analyzer (DMA) (Model 3071, TSI Inc.) connected to a Condensation Particle Counter (CPC) (Model 3022, TSI Inc.). Large particles $(>0.5 \mu \mathrm{m})$ were measured using an Aerodynamic Particle Sizer (APS) (Model 3320, TSI Inc.). Size distributions from $0.01 \mu \mathrm{m}$ to $20 \mu \mathrm{m}$ were collected as 15 minute averages.

$\mathrm{CCN}$ concentrations were measured with the University of Toronto thermal gradient diffusion chamber (TGDC). The instrument has been validated through a number of laboratory studies on inorganic, organic, and internally mixed aerosol particles (Kumar et al., 2003; Broekhuizen et al., 2004a, b; Abbatt et al., 2005) and is described in detail elsewhere (Kumar et al., 2003). Briefly, it is a continuous flow chamber consisting of two parallel wetted copper plates held at different temperatures resulting in a supersaturation in the center of the flow. The particle flow $(\sim 0.2 \mathrm{LPM})$ is entrained into the center of the chamber via a humidified sheath flow $(\sim 1.8 \mathrm{LPM})$ and is sampled at the end of the chamber by an APS (Model 3320, TSI Inc.) which pumps at 1.0 LPM. A diaphragm pump (Model 107CEF075, Thomas Industries, Inc.) pumped the remaining chamber effluent (1.0 LPM). Filter paper was used to wet the copper plates and was routinely remoistened to prevent drying and to maintain a constant supersaturation in the chamber. The chamber was operated at $0.58 \%$ supersaturation for the entire campaign and was routinely calibrated with monodisperse ammonium sulfate particles to ensure a stable supersaturation. $\mathrm{CCN}$ concentrations were collected every minute and were combined into $15 \mathrm{~min}$ averages to correspond with the other instrumentation sample times. The raw $\mathrm{CCN}$ counts were multiplied by a factor of 10 to account for dilution in the chamber by the particle free sheath flow and then multiplied by 1.4. This value of 1.4 has been shown to be robust for all particle sizes and compositions in previous laboratory studies with this chamber (Kumar et al., 2003; Broekhuizen et al., 2004a, b; Abbatt et al., 2005) and was verified by calibration with ammonium sulfate. Counting inefficiency of liquid droplets in the APS is a likely cause of this correction factor (Volckens and Peters, 2005). A schematic of the sampling setup is shown in Fig. 2.

Gas-phase measurements were also performed in $15 \mathrm{~min}$ sampling intervals. $\mathrm{SO}_{2}$ was measured using a fluorescent $\mathrm{SO}_{2}$ analyzer (Model 100A, API Inc.). Other gas-phase and particle measurements were used in the receptor modeling study and can be found in Buset et al. (2005) $)^{1}$.

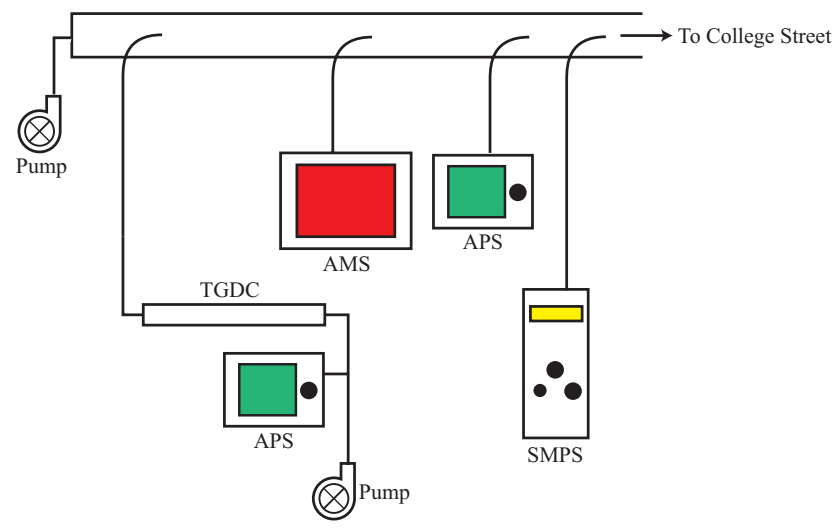

Fig. 2. Schematic of the experimental setup.

\section{Results}

\section{1 $\mathrm{CCN}$ and AMS measurements}

$\mathrm{CCN}$ measurements were performed on 10 days between 27 August and 17 September 2003. However, on only 4 of the 10 days (27 August, 5 September, 15 September, and 16 September) were the SMPS and AMS instruments also collecting data. All four days were weekdays and therefore influenced by high vehicle traffic loads. CCN concentrations were quite variable, ranging from $144 \mathrm{~cm}^{-3}$ on 5 September to $3291 \mathrm{~cm}^{-3}$ on 16 September.

The CCN concentrations fall within the values seen in other studies and are representative of concentrations observed in both remote marine environments (e.g. Hegg et al., 1991, 1995; Hudson, 1993) and also those observed under conditions of heavy anthropogenic influence (e.g. Hudson and Frisbie, 1991; Hitzenberger et al., 1999). That the CCN concentrations varied by a factor of 30 over the course of this study allows the closure methodology to be vigorously tested over a variety of conditions.

The AMS data consistently show a large organic fraction for particle sizes less than approximately $0.25 \mu \mathrm{m}$ as shown for two sample days in Fig. 3. Figure 4 shows a breakdown of the organic fraction for the same time periods shown in Fig. 3. 27 August and 5 September do not exhibit distinct bimodal behavior as seen in Fig. 3a. The inorganic mass fraction remains relatively constant over the entire size range. However, on 15 and 16 September two distinct particle modes are observed. The smaller mode is characterized by low inorganic mass loading and consistently low values for $m / z=44\left(\mathrm{CO}_{2}^{+}\right)$which is a marker for oxidatively processed species. This suggests a significant local source of hydrocarbon-like organic (HOC) emissions often associated with primary emission sources, such as vehicles (Zhang et al., 2005a, b). The larger mode, or accumulation mode is characterized by significantly higher inorganic mass loading and higher values for $m / z=44\left(\mathrm{CO}_{2}^{+}\right)$. These accumulation mode particles are likely aged particles from upwind sources 


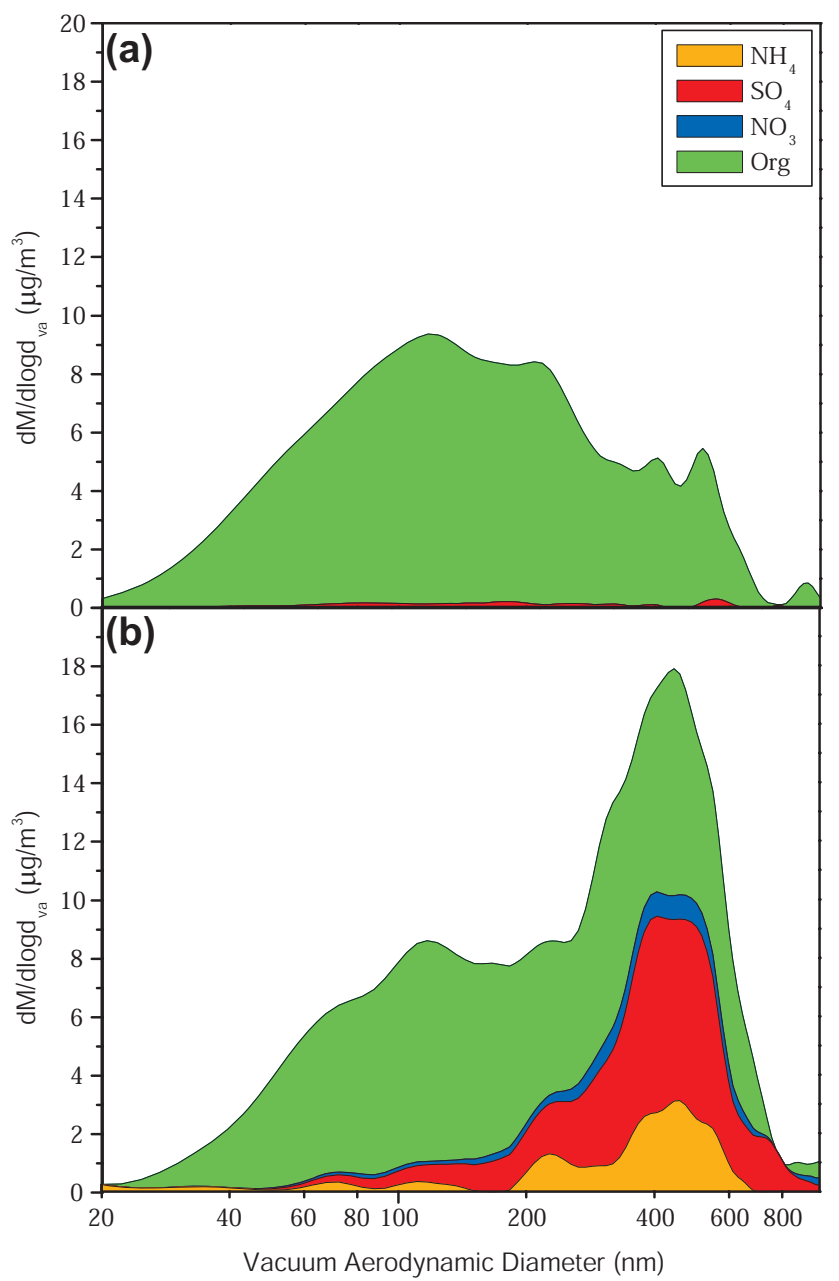

Fig. 3. AMS TOF spectra for two days showing mass concentrations vs. vacuum aerodynamic diameter. Green represents the organic fraction, red represents sulfate, blue represents nitrate, and orange represents ammonium. For example, the organic fraction in (b) at $0.5 \mu \mathrm{m}$ is approximately $7 \mu \mathrm{g} / \mathrm{m}^{3}$, not $17 \mu \mathrm{g} / \mathrm{m}^{3}$. (a) Hour 20:00-21:00 UTC, 5 September 2003. (b) Hour 16:00-17:00 UTC, 15 September 2003.

(Zhang et al., 2005a, 2b). The relative contributions of these two distinct particle modes on aerosol/CCN closure must be taken into account. This demonstrates the importance of both size resolved mass analysis and particle mixing state for successful aerosol/CCN closure at sites strongly impacted by local emissions.

\subsection{Comparison of CCN concentrations to SMPS measure- ments}

In the simplest closure analysis, the AMS TOF data were used, in combination with the number size distributions measured with the SMPS, to calculate predicted CCN concentrations. Briefly, the AMS compositional data were used to predict an onset activation diameter $D^{*}$ at the supersaturation

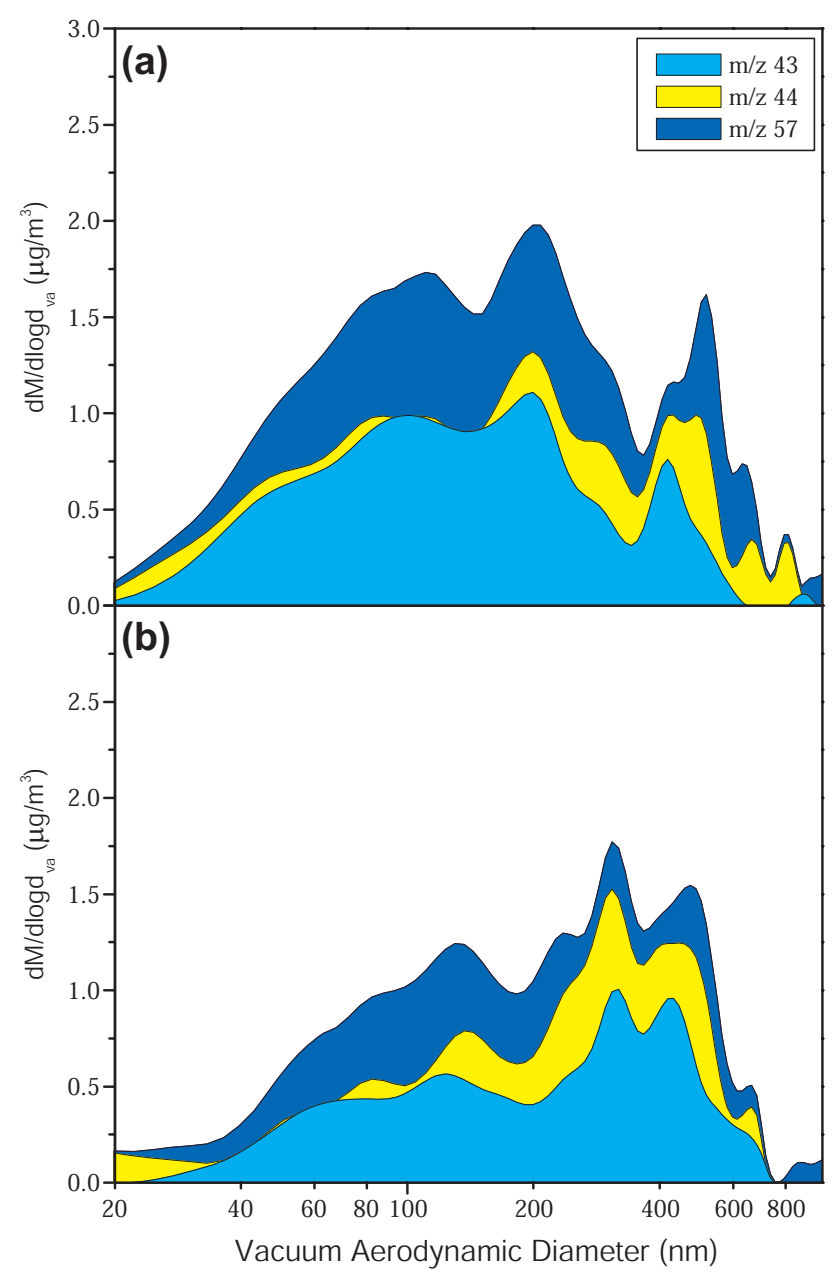

Fig. 4. AMS TOF spectra for two days showing key peaks in the organic mass fraction vs. vacuum aerodynamic diameter. The mass peak $(m / z=44 \mathrm{amu})$ is representative of aged organics, while the peak $(m / z=57 \mathrm{amu})$ is representative of primary emissions. The light blue represents $m / z=43$, the yellow represents $m / z=44$, and the dark blue represents $m / z=57$. (a) Hour 20:00-21:00 UTC, 5 September 2003. (b) Hour 16:00-17:00 UTC, 15 September 2003.

used in the CCN measurements. Then the SMPS particle counts were integrated for all sizes greater than or equal to $D^{*}$. The predicted CCN concentrations are then compared to the measured $\mathrm{CCN}$ concentration to determine whether closure is attained. Overall, this approach assumes full internal mixing of the aerosol.

The AMS TOF data were collected as a vacuum aerodynamic diameter, $D_{v a}$, which must be converted to a mobility diameter, $D_{m}$, for comparison with the SMPS data. For simplicity, the particles were assumed to be spherical with a bulk density, $\rho_{B}$, of $1.0 \mathrm{~g} \mathrm{~cm}^{-3}$. This assumption was verified by comparing SMPS derived particle volumes to AMS TOF data. These two data sets are correlated by effective density, which includes both the shape factor and bulk particle density. In general, the effective density of the organic rich 
particles was approximately equal to 1 (see Fig. 5).

For each TOF size bin, a soluble volume fraction, $V_{\text {sol }}$, was calculated according to Eq. (1)

$V_{\mathrm{sol}}=\frac{m_{\mathrm{sol}} / \rho_{\mathrm{sol}}}{m_{\mathrm{sol}} / \rho_{\mathrm{sol}}+m_{\mathrm{org}} / \rho_{\mathrm{org}}}$

where $m_{\text {sol }}$ and $\rho_{\text {sol }}$ are the total inorganic mass and the density of the inorganic fraction, respectively, and $m_{\text {org }}$ and $\rho_{\text {org }}$ are the organic fraction mass and density, respectively. An organic volume fraction, $V_{\text {org }}$, was calculated in a similar fashion. The soluble fraction was assumed to be ammonium sulfate in all cases $\left(\rho=1.77 \mathrm{~g} \mathrm{~cm}^{-3}\right)$ and the organic fraction was assumed to be completely insoluble $\left(\rho=1.0 \mathrm{~g} \mathrm{~cm}^{-3}\right)$. These are reasonable assumptions based on the observed $\mathrm{NH}_{4}^{+}-\mathrm{SO}_{4}^{2-}$ ratio and the effective density calculation described earlier.

The volume fractions, $V_{\text {sol }}$ and $V_{\text {org }}$, were used to calculate the number of moles of soluble material and the diameter of the insoluble core, respectively. These parameters were used in an insoluble core Köhler theory calculation to determine whether each AMS-TOF bin would activate at $0.58 \%$ supersaturation according to Eq. (2) (Seinfeld and Pandis, 1998)

$\ln \left(\frac{p_{w}\left(D_{p}\right)}{p^{\circ}}\right)=\frac{4 M_{w} \sigma_{w}}{R T \rho_{w} D_{p}}-\frac{6 n_{s} M_{w}}{\pi \rho_{w}\left(D_{p}^{3}-d_{u}^{3}\right)}$

where $p_{w}\left(D_{p}\right)$ is the droplet water vapor pressure, $\mathrm{p}^{\circ}$ is the equilibrium water vapor pressure, $M_{w}, \rho_{w}$, and $\sigma_{w}$ are the molecular weight, density, and surface tension of water, respectively, $R$ is the gas constant, $T$ is the droplet temperature, $n_{s}$ is the moles of solute, $D_{p}$ is the droplet diameter, and $d_{u}$ is the insoluble core diameter. The smallest size bin which would activate was designated as the onset activation diameter, $D^{*}$. In these calculations, every aerosol size bin larger than $D^{*}$ also activated, although it would be possible for particles larger than $D^{*}$ to be CCN inactive under certain conditions, e.g. very organic rich. The $15 \mathrm{~min}$ SMPS averages were integrated for all sizes larger than $D^{*}$ to obtain the predicted CCN concentration. There is a degree of uncertainty with each point in this calculation due to the fact that the AMS TOF data are hourly averages rather than $15 \mathrm{~min}$ averages, however, there was no significant difference when hourly CCN and SMPS averages were used instead of 15 min averages.

To assess the effect that externally mixed aerosol may have on the degree of closure, a second analysis was performed for the two days which showed bimodal distributions. On these two days, 15 and 16 September, two log-normal distributions were fit to the AMS TOF bimodal distribution for each time period. An effective density of $1.0 \mathrm{~g} \mathrm{~cm}^{-3}$ was assumed for the small particle mode. This assumption was verified by fitting SPMS derived particle volumes to two lognormal distributions and comparing these distributions with those from the AMS TOF data. The log-normal fit of the SMPS small mode, organic-rich fraction correlated very well

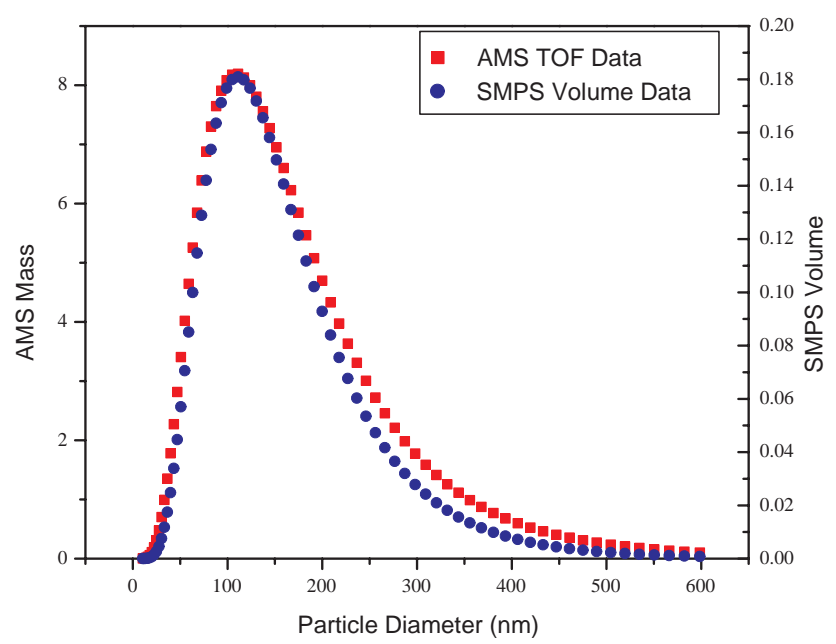

Fig. 5. Log-normal fits to the small mode, organic-rich fraction for 16:00-17:00 UTC, 15 September 2003. The red squares represent the fit to the AMS TOF data and the x-axis is $D_{v a}$. The blue circles represent the fit to SMPS volume data and the x-axis is $D_{m}$.

with the same mode from the AMS data. This suggests that an effective density assumption of $1.0 \mathrm{~g} \mathrm{~cm}^{-3}$ is valid for this mode. An example of the AMS-SMPS small mode correlation from 15 September is shown in Fig. 5. Unfortunately, the same comparison could not be performed for the larger mode since the SMPS data was only collected up to the $254 \mathrm{~nm}$ size bin. The SMPS data does not include the peak of the larger, sulfate-rich mode, so direct comparison is difficult. We estimate based on log-normal fits to the SMPS volume data and AMS TOF data that the effective density of the larger mode is between 1.4 and $1.6 \mathrm{~g} \mathrm{~cm}^{-3}$. Therefore, the larger particle mode was assumed to have a density of $1.5 \mathrm{~g} \mathrm{~cm}^{-3}$. The accumulation mode was assumed to have a uniform composition over the entire size range for simplicity and the particle diameters were reduced by a factor of 1.5 to convert aerodynamic diameter to mobility diameter. The two modes could then be completely decoupled from one another.

The onset activation diameter for both modes was calculated using the methodology described above. After the onset activation diameters were calculated for each mode, the SMPS size distributions were also divided into the two modes for each SMPS size bin. The total mass of each mode at each size was divided by the assumed density to obtain the relative particle volumes in each mode. The relative volumes in each mode were used to calculate the number of particles in each mode for each SMPS size bin.

It should be noted that for a small number of data points (i.e. $11 \%$ of the total) in the smaller mode, not all size bins larger than $D^{*}$ activated when the particle modes were decoupled. This is likely an artifact due to the assumptions made in decoupling the two modes and, because its effect on the degree of closure is well within the overall uncertainties described below, it has been disregarded in the analysis. Each 


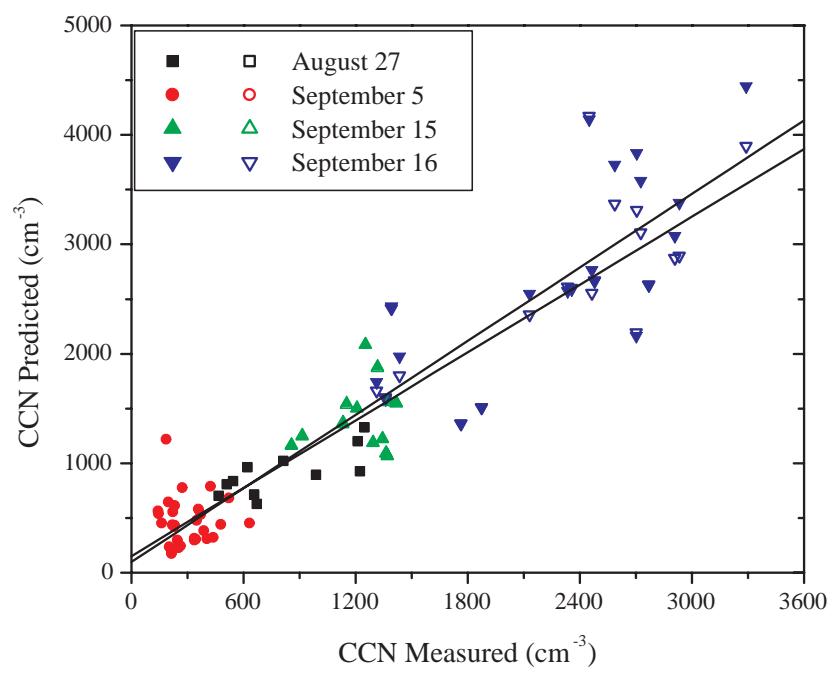

Fig. 6. Predicted $\mathrm{CCN}$ concentration vs. measured $\mathrm{CCN}$ concentrations for the four sample days. The filled symbols $(\boldsymbol{\square})$ are for predicted $\mathrm{CCN}$ concentrations based on the internally mixed assumption (see text). The open symbols $(\square)$ are for predicted CCN concentrations based on two particle modes on September 15 and 16 (see text). The black lines are linear least squares fits of the two data sets (slope $=1.12 \pm 0.05$; slope $=1.03, \pm 0.05$ ).

mode was integrated for all particles sizes larger than the activation onset diameter, $D^{*}$, and the sum of the contribution of each mode yielded the total $\mathrm{CCN}$ concentration.

Figure 6 shows that the ratio of $\mathrm{CCN}_{\text {predicted }}$ to $\mathrm{CCN}_{\text {observed }}$ is $1.12 \pm 0.05$ for the simple closure calculation assuming internal mixing. However, under the assumption of external mixing, the ratio of $\mathrm{CCN}_{\text {predicted }}$ to $\mathrm{CCN}_{\text {observed }}$ decreases to $1.03 \pm 0.05$. Error bars were not included for figure clarity, however, the uncertainties in the measured CCN concentrations are estimated to be $\pm 10 \%$ based on previous studies (Kumar et al., 2003). The largest uncertainty for the closure analysis is in the predicted CCN concentrations, estimated at $\pm 25 \%$ based on uncertainties in the chamber supersaturation used to calculate $D^{*}$, the SMPS size distributions, the AMS data, the assumed density and composition of the aerosol particles. Note that the standard error associated with each slope is not as large. Both analyses yield closure within experimental uncertainties, however, the assumption of external mixing is probably more realistic. In the external mixing scenario, there are significant contributions to the total number of $\mathrm{CCN}$ from both the accumulation and small particle modes.

A sensitivity analysis was also performed to investigate the effect of uncertainties in chamber supersaturation, organic solubility, and surface tension on the aerosol/CCN closure. The calculation described above assuming external mixing was performed for chamber supersaturations between $0.56 \%$ and $0.60 \%$. The ratio of $\mathrm{CCN}_{\text {predicted }}$ to $\mathrm{CCN}_{\text {observed varied }}$ from $1.01 \pm 0.04$ to $1.08 \pm 0.05$ under these chamber super- saturation conditions. The sensitivity of the closure analysis to droplet surface tension was also investigated. The surface tension of the growing droplet was assumed to be constant and $10 \%$ lower than the surface tension of pure water, or $0.065 \mathrm{~N} / \mathrm{m}$. The ratio of $\mathrm{CCN}_{\text {predicted }}$ to $\mathrm{CCN}_{\text {observed }}$ with the lowered surface tension was $1.20 \pm 0.06$. Finally, the effect of organic solubility was investigated. Two analyses were performed. In the first, the organic carbon in all the particles was assumed to be $10 \%$ soluble by mass. In the second analysis, the smaller mode was assumed to be completely insoluble and the larger mode was assumed to have $10 \%$ soluble organic mass. In both cases, the soluble organic component was assumed to be adipic acid, which was chosen because its solubility is representative of soluble organic compounds found in the atmosphere. The ratios of $\mathrm{CCN}_{\text {predicted }}$ to $\mathrm{CCN}_{\text {observed }}$ for these analyses were $1.16 \pm 0.06$ and $1.04 \pm 0.05$, respectively. The overall conclusion to be made is that if the particles are assumed to have $10 \%$ by mass soluble organic content or a $10 \%$ lower surface tension, then closure is still obtained within experimental uncertainties. Much higher soluble water contents or lower surface tensions would significantly degrade the degree of closure obtained. We note that similar conclusions have been recently obtained in the as-yet unpublished work of Medina et al. (2005) referred to above. In particular, in that work a similar degree of $\mathrm{CCN}$ closure is obtained using AMS aerosol compositions assuming full organic insolubility and a surface tension equal to water for the growing droplet.

\section{Discussion}

The aerosol mass concentrations in downtown Toronto can vary widely, but were often characterized during this study by high concentrations of primary organic emissions in the size range below $0.25 \mu \mathrm{m}$. CCN concentrations were also highly variable, ranging from approximately $100 \mathrm{~cm}^{-3}$ to $4000 \mathrm{~cm}^{-3}$. Aerosol/CCN closure has been achieved under the stated assumptions for the entire range of $\mathrm{CCN}$ concentrations using size-resolved particle mass concentrations measured with the Aerodyne AMS. It should be noted that there is not a strong correlation between observed and measured CCN for 5 September, however, the CCN concentration is not systematically over- or under-predicted on this day. To our knowledge, this is the first aerosol/CCN closure study which has been able to achieve closure for an aerosol population that is strongly influenced by anthropogenic emissions. In addition to the Medina et al. (2005) study referred to above, it is the first to directly use AMS size-resolved composition data to study aerosol/CCN closure.

Previous laboratory studies (e.g. Bilde and Svenningsson, 2004; Broekhuizen et al., 2004a) have shown that, for a relatively insoluble organic particle, small amounts of a highly soluble inorganic species such as ammonium sulfate or sodium chloride have a large effect on the particle dry 
diameter needed for activation. In fact, a particle with a mass fraction of only $15-20 \%$ ammonium sulfate can be reasonably modeled under the assumption that it is pure ammonium sulfate. Furthermore, recent studies (Broekhuizen et al., 2004b; Abbatt et al., 2005) have shown that while organic particle oxidation can affect $\mathrm{CCN}$ activation, significant organic surface tension effects have not yet been demonstrated in the laboratory, especially when highly soluble species are also present. Aerosol solubility appears to be the driving force behind $\mathrm{CCN}$ activation in most cases. Mircea et al. (2005) have recently proposed that the water soluble organic carbon fraction must be reasonably well characterized to accurately predict particle hygroscopic growth and activation. The impact of water soluble organic carbon in this study, however, is minimal since any soluble organic carbon will likely be found in the accumulation mode which is already dominated by sulfate. The sensitivity analyses performed show that the closure result is fairly insensitive to the chamber supersaturation. However, the analysis is sensitive to the water soluble organic content and surface tension of the droplets. It is likely that the water soluble organic carbon is contained predominantly in the larger particle mode and not in the smaller mode due to the probable sources and histories of the two modes. Under this assumption, the closure is not significantly impacted due to the fact that the onset activation diameter of the larger mode is dominated by the large mass fraction of ammonium sulfate. A reduction in droplet surface tension also has a significant impact on closure, however, it is difficult to speculate on the surface tension of growing droplets in the field. Laboratory studies have not conclusively quantified the impact of atmospherically relevant surface active species on particle activation.

The aerosol/CCN closure studies which have been successful in achieving closure (Liu et al., 1996; Cantrell et al., 2001; Roberts et al., 2002, VanReken et al., 2003) have seen high levels of sulfate, generally larger than $50 \%$ by mass. Only the Roberts et al. (2002) study saw significant organic mass fractions (approx. 80\%), half of which were estimated to be water soluble. The latter study's CCN concentrations were well modeled using a three-component model; however, the model assumed a completely insoluble organic fraction. In these studies, data for which closure was not achieved were often characterized by large anthropogenic contributions or high organic mass loading.

To further aid the interpretation of the present closure study, back trajectory calculations were performed for the four sample days using the National Oceanic and Atmospheric Administration's (NOAA) Hybrid Single-Particle Lagrangian Integrated Trajectory (HYSPLIT) model (http: //www.arl.noaa.gov/ready/hysplit4.html, NOAA Air Resources Laboratory, Silver Spring, Maryland). Ground-level, 48-hour back trajectories were calculated at noon for each of the four sample days using the CDC1 global reanalysis meteorological data. As seen in Fig. 7, the days which experienced low CCN concentrations, 27 August and 5 Septem-

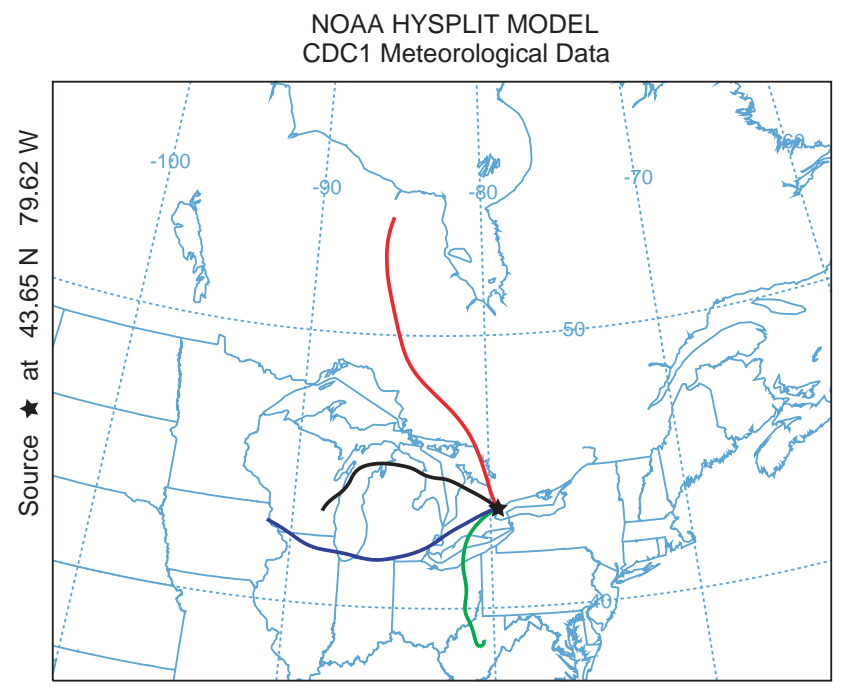

Fig. 7. Simulated $48 \mathrm{~h}$ back trajectories for the four sample days. The sample trajectories end at 16:00 UTC for all four days. (black line) 27 August; (red line) 5 September; (green line) 15 September; (blue line) 16 September. This plot is a product of the NOAA Air Resources Laboratory HYSPLIT model.

ber, had air mass origins in northern Michigan and northern Ontario, respectively. This was evidenced by low sulfate and nitrate particulate mass loading, and low $\mathrm{SO}_{2}$ concentrations. The particulate mass on those two days was extremely organic-rich and was likely the result of fresh local emissions only. 15 September saw air masses from southern Ontario, and Cleveland, Ohio, while 16 September showed trajectories from Detroit, Michigan and Chicago, Illinois. These two days had elevated $\mathrm{SO}_{2}$ gas-phase concentrations, higher sulfate and nitrate particulate mass loading, high CCN concentrations and significant upwind and local anthropogenic influence. The AMS TOF size spectra show that most of the sulfate and nitrate mass was found in the larger accumulation mode with diameters larger than $0.25 \mu \mathrm{m}$. The majority of the particles were below $0.25 \mu \mathrm{m}$ and showed strong signatures of local primary anthropogenic organic emissions (Fig. 4b). The organic-rich, locally derived particles and aged particles from upwind sources both contributed to the measured $\mathrm{CCN}$, as evidenced by higher $\mathrm{CCN}$ concentrations on those two days.

Few other ground based studies and almost no airborne studies have achieved closure, and most have overpredicted $\mathrm{CCN}$ concentrations. It is difficult to assess the reason for these discrepancies; however, airborne $\mathrm{CCN}$ measurements are more difficult and may be subject to measurement errors related to rapidly changing conditions and insufficient time or spatial resolution. Incomplete or missing composition information is often cited as a reason for overprediction as well. The recent advances in high time-resolution aerosol mass spectrometric techniques such as AMS or ATOFMS and the increasing ability to measure the composition of 
single aerosol particles may allow aerosol/CCN closure to be achieved in a wider variety of conditions and experimental platforms. Simultaneous RH-TDMA experiments can also determine aerosol mixing state and soluble organic carbon (Rissler et al., 2004). It is clear that detailed, size-resolved mass fractions and particle mixing state information may be required to achieve closure under some conditions.

\section{Conclusions}

Aerosol/CCN closure has been achieved under the assumptions stated (i.e. organic insolubility, surface tension of water, either full internal mixing or external mixing of two modes) using an insoluble core Köhler model based on size resolved AMS TOF particle mass concentrations and SMPS derived size distributions. In addition to Medina et al. (2005), this is the first study to explicitly use AMS TOF data to achieve aerosol/CCN closure and is also the first study to achieve closure under conditions of high anthropogenic emissions. This study has provided further evidence that small amounts of soluble inorganic material such as sulfate can drive the $\mathrm{CCN}$ activity of organic rich particles. Clearly, more laboratory and field work is needed to ascertain the impact of oxidation on the organic rich particles seen in urban environments or near biomass burning sites. The impact of surface tension also needs to be further elucidated. However, the increasing use of particle mass spectrometry in field and laboratory studies and the increasing development of quantitative single particle techniques shows great promise in allowing aerosol/CCN closure to be achieved on both ground based and airborne platforms.

It should be noted that, like other field studies, the particles have not been completely characterized in this study. The mixing state, composition, and surface tension of the particles are not fully known and therefore, the closure analysis must be viewed with this in mind. The size-resolved composition information and mixing state assumptions are another step toward full characterization of the particles and definitive aerosol/CCN closure.

Cloud droplet formation is a complicated process involving many chemical, physical, and dynamic factors, and the ability to achieve aerosol/CCN closure is a very important step in the goal of incorporating accurate and detailed cloud formation parameters into global climate models.

Acknowledgements. This work was funded with financial support from the Canadian Foundation of Climate and Atmospheric Sciences, the Canada Foundation for Innovation and NSERC, including an NSERC PGS-M award to R. Y.-W. Chang. The authors are grateful to G. Evans for housing the instruments during the measurement campaign. They are grateful to the paper's reviewers, especially G. McFiggans, for constructive criticism and suggestions for data analysis improvement.
Edited by: A. Nenes

\section{References}

Abbatt, J. P. D., Broekhuizen, K., and Kumar, P. P.: Cloud condensation nucleus activity of internally mixed ammonium sulfate/organic acid aerosol particles, Atmos. Environ., 39, 47674778, 2005.

Albrecht, B.: Aerosols, cloud microphysics and fractional cloudiness, Science, 245, 1227-1230, 1989.

Alfarra, M. R., Coe, H., Allan, J. D., et al.: Characterization of urban and rural organic particulate in the Lower Fraser Valley using two Aerodyne Aerosol Mass Spectrometers, Atmos. Environ., 38, 5745-5758, 2004.

Allan, J. D., Alfarra, M. R., Bower, K. N., et al.: Quantitative sampling using an Aerodyne aerosol mass spectrometer -2 . Measurements of fine particulate chemical composition in two U.K. cities, J. Geophys. Res.-Atmos., 108, 4091, doi:10.1029/2002JD002359, 2003.

Bigg, E. K.: Discrepancy between observation and prediction of concentrations of cloud condensation nuclei, Atmos. Res., 20, 82-86, 1986.

Bilde, M. and Svenningsson, B.: CCN activation of slightly soluble organics: Importance of small amounts of inorganic salt and particle phase, Tellus, Ser. B, 56, 128-134, 2004.

Broekhuizen, K., Kumar, P. P., and Abbatt, J. P. D.: Partially soluble organics as cloud condensation nuclei: Role of trace soluble and surface active species, Geophys. Res. Lett., 31, L01107, doi:10.1029/2003GL018203, 2004a.

Broekhuizen, K., Thornberry, T., Kumar, P. P., and Abbatt, J. P. D.: Formation of cloud condensation nuclei by oxidative processing: Unsaturated fatty acids, J. Geophys. Res.-Atmos., 109, D24206, doi:10.1029/2004JD005298, 2004b.

Cantrell, W., Shaw, G., Cass, G. R., Chowdhury, Z., Hughes, L. S., Prather, K. A., Guazzotti, S. A., and Coffee, K. R.: Closure between aerosol particles and cloud condensation nuclei at Kaashidhoo Climate Observatory, J. Geophys. Res., 106, 28 711-28 718, 2001.

Chuang, P. Y., Collins, D. R., Pawlowska, H., Snider, J. R., Jonsson, H. H., Brenguier, J.-L., Flagan, R. C., and Seinfeld, J. H.: CCN measurements during ACE-2 and their relationship to cloud microphysical properties, Tellus, Ser. B, 52, 843-867, 2000.

Chung, C. E. and Ramanathan, V.: Aerosol loading over the Indian Ocean and its possible impact on regional climate, Indian J. Mar. Sci., 33, 40-55, 2004.

Corrigan, C. E. and Novakov, T.: Cloud condensation nucleus activity of organic compounds: a laboratory study, Atmos. Environ., 33, 2661-2668, 1999.

Covert, D. S., Gras, J. L., Wiedensohler, A., and Stratmann, F.: Comparison of directly measured $\mathrm{CCN}$ with $\mathrm{CCN}$ modeled from the number-size distribution in the marine boundary layer during ACE 1 at Cape Grim, Tasmania, J. Geophys. Res., 103, 16597$16608,1998$.

Cruz, C. N. and Pandis, S. N.: A study of the ability of pure secondary organic aerosol to act as cloud condensation nuclei, Atmos. Environ., 31, 2205-2214, 1997.

Durkee, P. A., Noone, K. J., Bluth, R. T., et al.: The impact of shipproduced aerosols on the microstructure and albedo of warm ma- 
rine stratocumulus clouds: A test of MAST hypotheses 1i and 1ii, J. Atmos. Sci., 57, 2554-2569, 2000.

Dusek, U., Covert, D. S., Wiedensohler, A., Neususs, C., Weise, D., and Cantrell, W.: Cloud condensation nuclei spectra derived from size distributions and hygroscopic properties of the aerosol in coastal south-west Portugal during ACE-2, Tellus, Ser. B, 55, 35-53, 2003.

Facchini, M. C., Mircea, M., Fuzzi, S., and Charlson, R. J.: Cloud albedo enhancement by surface-active organic solutes in growing droplets, Nature, 401, 257-259, 1999.

Gerber, H. E., Hoppel, W. A., and Wojciechowski, T. A.: Experimental verification of the theoretical relationship between size and critical supersaturation of salt nuclei, J. Atmos. Sci., 34, 1836-1841, 1977.

Giebl, H., Berner, A., Reischl, G., Puxbaum, H., Kasper-Giebl, A., and Hitzenberger, R.: CCN activation of oxalic acid and malonic acid test aerosols with the University of Vienna cloud condensation nuclei counter, J. Aerosol Sci., 33, 1623-1634, 2002.

Givati, A. and Rosenfeld, D.: Quantifying precipitation suppression due to air pollution, J. Appl. Meteorol., 43, 1038-1056, 2004.

Hegg, D. A., Radke, L. F., and Hobbs, P. V.: Measurements of Aitken nuclei and cloud condensation nuclei in the marine atmosphere and their relation to the DMS-cloud-climate hypothesis, J. Geophys. Res., 96, 18 727-18 733, 1991.

Hegg, D. A., Ferek, R. J., and Hobbs, P. V.: Cloud condensation nuclei over the Arctic Ocean in early spring, J. Appl. Meteorol., 34, 2076-2082, 1995.

Hitzenberger, R., Berner, A., Giebl, H., Kromp, R., Larson, S. M., Rouc, A., Koch, A., Marischka, S., and Puxbaum, H.: Contribution of carbonaceous material to cloud condensation nuclei concentrations in European background (Mt. Sonnblick) and urban (Vienna) aerosols, Atmos. Environ., 33, 2647-2659, 1999.

Hudson, J. G.: Cloud condensation nuclei near marine cumulus, J. Geophys. Res., 98, 2693-2702, 1993.

Hudson, J. G. and Frisbie, P. R.: Surface cloud condensation nuclei and condensation nuclei measurements at Reno, Nevada, Atmos. Environ., Part A, 25, 2285-2299, 1991.

Jayne, J. T., Leard, D. C., Zhang, Z. F., Davidovits, P., Smith, K. A., Kolb, C. E., and Worsnop, D. R.: Development of an aerosol mass spectrometer for size and chemical composition analysis of submicron particles, Aerosol Sci. Tech., 33, 49-70, 2000.

Jimenez J. L., Jayne, J. T., Shi, Q., et al.: Ambient aerosol sampling using the aerodyne aerosol mass spectrometer, J. Geophys. Res.Atmos., 108, 8425, doi:10.1029/2001JD001213, 2003.

Katz, U. and Kocmond, W. C.: An investigation of the sizesupersaturation relationship of soluble condensation nuclei, J. Atmos. Sci., 30, 160-165, 1973.

Kumar, P. P., Broekhuizen, K., and Abbatt, J. P. D.: Organic acids as cloud condensation nuclei: Laboratory studies of highly soluble and insoluble species, Atmos. Chem. Phys., 3, 509-520, 2003, http://www.atmos-chem-phys.net/3/509/2003/.

Laaksonen, A., Korhonen, P., Kulmala, M., and Charlson, R. J.: Modification of the Köhler equation to include soluble trace gases and slightly soluble substances, J. Atmos. Sci., 55, 853862,1998

Liu, P. S. K., Leaitch, W. R., Banic, C. M., Li, S.-M., Ngo, D., and Megaw, W. J.: Aerosol observations at Chebogue Point during the 1993 North Atlantic Regional Experiment: Relationships among cloud condensation nuclei, size distribution, and chem- istry, J. Geophys. Res., 101, 28 971-28 990, 1996.

Martin, G. M., Johnson, D. W., and Spice, A.: The measurement and parameterization of effective radius of droplets in warm stratocumulus clouds, J. Atmos. Sci., 51, 1823-1842, 1994.

Mircea, M. , Facchini, M. C., Decesari, S., Cavalli, F., Emblico, L., Fuzzi, S., Vestin, A., Rissler, J., Swietlicki, E., Frank, G., Andreae, M. O., Maenhaut, W., Rudich, Y., and Artaxo, P.: Importance of the organic aerosol fraction for modeling aerosol hygroscopic growth and activation: a case study in the Amazon Basin, Atmos. Chem. Phys., 5, 3111-3126, 2005, http://www.atmos-chem-phys.net/5/3111/2005/.

Murphy, D. M., Thomson, D. S., and Mahoney, M. J.: In-situ measurements of organics, meteoritic material, mercury and other elements in aerosols at 5 and 19 kilometers, Science, 282, 1664 1669, 1998.

Quinn, P. K., Covert, D. S., Bates, T. S., Kapustin, V. N., RamseyBell, D. C., and McInnes, L. M.: Dimethylsulfide/cloud condensation nuclei/climate system: relevant size-resolved measurements of the chemical and physical properties of atmospheric aerosol particles, J. Geophys. Res., 98, 10 411-10 427, 1993.

Raymond, T. M. and Pandis S. N.: Cloud activation of singlecomponent organic aerosol particles, J. Geophys. Res., 107, 4787, doi:10.1029/2002JD002159, 2002.

Raymond, T. M. and Pandis, S. N.: Formation of cloud droplets by multicomponent organic particles, J. Geophys. Res., 108, 4469, doi:10.1029/2003JD003503, 2003.

Rissler, J. , Swietlicki, E., Zhou, J., Roberts, G., Andreae, M. O., Gatti, L. V. and Artaxo, P.: Physical properties of the submicrometer aerosol over the Amazon rain forest during the wetto-dry season transition - comparison of modeled and measured CCN concentrations, Atmos. Chem. Phys., 4, 2119-2143, 2004, http://www.atmos-chem-phys.net/4/2119/2004/.

Rissman, T. A., VanReken, T. M., Wang, J., Gasparini, R., Collins, D. R., Jonsson, H. H., Brechtel, F. J., Flagan, R. C., and Seinfeld, J. H.: Characterization of ambient aerosol from measurements of cloud condensation nuclei (CCN) during the 2003 Atmospheric Radiation Measurement (ARM) Aerosol Intensive Observational Period (IOP) at the Southern Great Plains (SGP) Site in Oklahoma, J. Geophys. Res.-Atmos., 111, D05S11, doi:10.1029/2004JD005695, 2006.

Roberts, G. C., Artaxo, P., Zhou, J., Swietlicki, E., and Andreae, M. O.: Sensitivity of CCN spectra on chemical and physical properties of aerosol: A case study from the Amazon Basin, J. Geophys. Res., 107, 8070, doi:10.1029/2001JD00583, 2002.

Rosenfeld, D.: TRMM observed first direct evidence of smoke from forest fires inhibiting rainfall, Geophys. Res. Lett., 26, 31053108, 1999.

Rosenfeld, D.: Suppression of rain and snow by urban and industrial air pollution, Science, 287, 1793-1796, 2000.

Saxena, P. and Hildemann, L. M.: Water-soluble organics in atmospheric particles: A critical review of the literature and application of thermodynamics to identify candidate compounds, J. Atmos. Chem., 24, 57-109, 1996.

Seinfeld, J. H. and Pandis, S. N.: Atmospheric Chemistry and Physics: From Air Pollution to Climate Change, John Wiley \& Sons, Inc., New York City, NY, pp. 792, 1998.

Shulman, M. L., Jacobson, M. C., Carlson, R. J., Synovec, R. E., and Young, T. E.: Dissolution behavior and surface tension effects of organic compounds in nucleating cloud droplets, Geo- 
phys. Res. Lett., 23, 277-280, 1996.

Snider, J. R. and Brenguier, J.-L.: Cloud condensation nuclei and cloud droplet measurements during ACE-2, Tellus, Ser. B, 52, 828-842, 2000.

Snider, J. R., Guibert, S., Brenguier, J.-L., and Putaud, J.-P.: Aerosol activation in marine stratocumulus clouds: 2. Köhler and parcel theory closure studies, J. Geophys. Res., 108, 8629, doi:10.1029/2002JD002692, 2003.

Tan, P. V., Evans, G. J., Tsai, J., Owega, S., Fila, M., Malpica, O., and Brook, J. R.: On-line analysis of urban particulate matter focusing on elevated wintertime aerosol concentrations, Environ. Sci. Tech. 36, 3512-3518, 2002.

Twomey, S.: Influence of pollution on the short-wave albedo of clouds, J. Atmos. Sci., 34, 1149-1152, 1977.

VanReken, T. M., Rissman, T. A., Roberts, G. C., Varutbangkul, V., Jonsson, H. H., Flagan, R. C., and Seinfeld, J.H.: Toward aerosol/cloud condensation nuclei (CCN) closure during CRYSTAL-FACE, J. Geophys. Res., 108, 4633, doi:10.1029/2003JD003582, 2003.

VanReken, T. M., Ng, N. L., Flagan, R. C., and Seinfeld, J. H.: Cloud condensation nucleus activation properties of biogenic secondary organic aerosol, J. Geophys. Res.-Atmos., 110, D07206, doi:10.1029/2004JD005465, 2005.

Volckens, J., and Peters, T. M.: Counting and particle transmission efficiency of the aerodynamic particle sizer, J. Aerosol Sci., 36, 1400-1408, 2005.
Wood, R., Johnson, D., Osborne, S., et al.: Boundary layer and aerosol evolution during the 3rd Lagrangian experiment of ACE2, Tellus Ser. B, 52, 401-422, 2000.

Zhang, Q., Alfarra, M. R., Worsnop, D. R., Allan, J. D., Coe, H., Canagaratna, M. R., and Jimenez, J. L.: Deconvolution and quantification of hydrocarbon-like and oxygenated organic aerosols based on aerosol mass spectrometry, Environ. Sci. Tech., 39, 4938-4952, doi:10.1021/es0485681, 2005a.

Zhang, Q., Worsnop, D. R., Canagaratna, M. R., and Jimenez, J. L.: Hydrocarbon-like and oxygenated organic aerosols in Pittsburgh: Insights into sources and processes of organic aerosols, Atmos. Chem. Phys., 5, 3289-3311, 2005 b.

Zhang, X., Smith, K. A., Worsnop, D. R., Jimenez, J. L., Jayne, J. T., Kolb, C. E., Morris, J., and Davidovits, P.: Numerical characterization of particle beam collimation: Part II Integrated aerodynamic-lens-nozzle system, Aerosol Sci. Tech., 38, 619638, 2004.

Zhou, J., Swietlicki, E., Berg, O. H., Aalto, P. P., Hämeri, K., Nilsson, E. D., and Leck, C.: Hygroscopic properties of aerosol particles over the central Arctic Ocean during summer, J. Geophys. Res., 106, 32 111-32 123, 2001. 